\title{
CONTEÚDOS DE ENSINO NA DISCIPLINA DE LÍNGUA PORTUGUESA: O EMBATE ENTRE O DISCURSO DA TRADIÇÃO E O DISCURSO DA MUDANÇA*
}

\author{
Nívea Rohling \\ Universidade Tecnológica Federal do Paraná \\ Curitiba, Paraná, Brasil
}

\begin{abstract}
Resumo: Este artigo apresenta uma análise de enunciados de licenciandos em Letras de um curso de Licenciatura Letras-Português-EaD de uma universidade pública federal do sul do Brasil no que se refere às concepções de conteúdos de ensino e aprendizagem na disciplina de língua portuguesa. A fundamentação teórico-metodológica insere-se na Análise Dialógica do Discurso do Círculo de Bakhtin. Os dados da pesquisa compõem-se de: 106 fóruns de discussão; 59 enunciados de atividades avaliativas, postados no ambiente virtual de ensino e aprendizagem no período de 2007 a 2011; e dados gerados por meio de um questionário, respondido por 61 licenciandos nos seus respectivos polos de apoio de ensino presencial. A análise aponta para um embate entre o discurso da tradição no ensino de língua portuguesa e o discurso da mudança.

Palavras-chave: Formação inicial de professor. Conteúdos de ensino e aprendizagem. Discurso da tradição.
\end{abstract}

1 INTRODUÇÃO

O presente artigo apresenta uma análise de enunciados de licenciandos em LetrasPortuguês na modalidade a distância de uma universidade pública do sul do Brasil sobre os conteúdos de ensino e aprendizagem na disciplina de Língua Portuguesa (doravante LP).

Para tanto, tomamos como base epistêmica e metodológica a concepção bakhtiniana de linguagem, de discurso, de gêneros do discurso e de enunciado (BAKHTIN, 1998[1975]; BAKHTIN, 2003[1979]; BAKHTIN [VOLOCHÍNOV], 2004[1929]). Os dados da pesquisa compõem-se de: 106 fóruns de discussão; 59 enunciados de atividades avaliativas, postados no ambiente virtual de ensino e aprendizagem no período de 2007 a 2011; e dados gerados por meio de um questionário, respondido por 61 licenciandos nos seus respectivos polos de apoio de ensino presencial.

Inicialmente, delinearemos o quadro teórico e metodológico em que nos inserimos, ou seja, a Análise Dialógica do Discurso (ADD). Em seguida, apresentaremos as regularidades encontradas no processo de análise dos dados,

\footnotetext{
* Este texto é resultado de uma pesquisa de doutoramento desenvolvida no Programa de Pós-Graduação em Linguística da Universidade Federal de Santa Catarina (UFSC) com financiamento do CNPq, sob a orientação da Profa. Dra. Rosângela Hammes Rodrigues.

** Professora Adjunta do Departamento Acadêmico de Comunicação e Expressão (DACEX); Doutora em Linguística pela Universidade Federal de Santa Catarina. Email: niveajoi@yahoo.com.br.
} 
evidenciando os embates entre o discurso da tradição no ensino e o discurso teórico, advindo das interações do curso e que representa o discurso da mudança.

\section{AS BASES EPISTÊMICAS E METODOLÓGICAS DA ANÁLISE DIALÓGICA DO DISCURSO}

A partir da década de 1990, houve um crescente interesse por parte de pesquisadores nacionais e internacionais, tanto na área dos Estudos da Linguagem como nas Ciências Humanas, em debruçar-se sobre questões filosóficas e questões inerentes à linguagem, tendo como lentes os conceitos advindos do Círculo de Bakhtin. Conceitos como enunciado, dialogismo, discurso e gêneros do discurso já estão, de certo modo, estabilizados nos espaços científico-acadêmicos sendo, pois, tematizados em trabalhos como: Brait (2006, 2007, 2009), Faraco (2003), Geraldi (2002[1991]), Miotello (2001), Ponzio (2008[1998]), Rodrigues (2001; 2005), entre outros.

Nesse contexto epistemológico, Brait (2006) argumenta em favor da constituição de uma teoria e metodologia para análise de discurso na perspectiva dialógica. Ao contextualizar essa teorização, a autora explica que não se pode afirmar que há, de fato, uma metodologia formalizada por Bakhtin para a análise do discurso, assim como fez a Análise do Discurso Francesa, por exemplo. O que ocorre é um movimento de recuperação de conceitos construídos ao longo dos textos bakhtinianos, que têm sido um norte para os estudos da linguagem de caráter histórico e social (BRAIT, 2006).

Na percepção de Brait (2007), grande parte dos estudos do Círculo de Bakhtin se dedica ao exame da linguagem estética, como nos trabalhos dedicados às obras de Rabelais e Dostoiévski, em que encontramos um elevado grau de teorização, tendo o romance como lugar privilegiado para a construção da arquitetônica teórica do Círculo. Porém, na teorização elaborada pelo Círculo, também há caminhos para se examinar a organicidade do discurso cotidiano, por exemplo, o que contribui significativamente para uma nova perspectiva a respeito da linguagem humana e aponta para formas outras de compreensão da produção de sentido. É possível dizer que a arquitetônica bakhtiniana fornece elementos que contribuem para um caminho, em outras palavras, horizontes possíveis para se estudar a linguagem e os discursos numa perspectiva dialógica.

Para definir esse horizonte teórico-metodológico, a autora escreve:

\footnotetext{
Sem querer (e sem poder) estabelecer uma definição fechada do que seria essa análise/teoria dialógica do discurso, uma vez que o fechamento significaria uma contradição em relação aos termos que a postulam, é possível explicar seu embasamento constitutivo, ou seja, a indissolúvel relação existente entre língua, linguagens, história e sujeitos que instaura os estudos da linguagem como lugares de produção de conhecimento de forma comprometida, responsável, e não apenas como procedimento submetido a teorias e metodologias dominantes em determinadas épocas. (BRAIT, 2006, p. 10).
}

Conforme se pode inferir da citação da linguista, a impossibilidade de fechamento, ou seja, de estabelecimento de uma metodologia de análise rígida, está no 
centro da postura bakhtiniana. Tal opção epistêmica não se reduz à aplicação de uma metodologia e validação de teorias, mas ao construto de conhecimentos relevantes e responsáveis no âmbito dos estudos da linguagem.

No empreendimento de construir parâmetros teórico-analíticos para se olhar o discurso em uma perspectiva dialógica, Brait (2006) expõe algumas peculiaridades de tais pesquisas. Primeiramente, a análise inclui um olhar particular para as práticas discursivas, isto é, para as enunciações concretas e, ao mesmo tempo, leva em conta os contextos mais amplos de produção e circulação dos discursos. O enfrentamento bakhtiniano da linguagem leva em conta as particularidades discursivas, que apontam para contextos mais amplos ao considerar os aspectos extralinguísticos imbricados. Outro ponto a ser observado é que em uma análise dialógica não há categorias a priori aplicáveis de forma mecânica a textos e discursos (BRAIT, 2006). Nessa perspectiva, as categorias emergem das relativas regularidades dos dados, que são observadas/apreendidas no percurso da pesquisa. Desse modo, não é possível aplicar as mesmas categorias de uma pesquisa realizada em outra, ainda em construção, pois o dado é sempre o discurso concreto e único proferido em um determinado espaço e tempo e por determinados interlocutores.

No âmbito da produção de conhecimento, certamente é necessário olhar o único, o singular, o evento que conduz a uma determinada regularidade. Essa relação entre o particular e o geral no âmbito da pesquisa relaciona-se ao que diz Ponzio (2010, p. 16):

resulta óbvio que o conhecimento deva ser necessariamente conhecimento do geral, procedendo por conceitos, por classificações, por montagem, sobre a base de conjuntos, de gêneros, nos quais o singular, de um modo ou de outro, reaparece sob a forma de indivíduo identificado pelo pertencimento a este ou àquele conjunto.

Além da busca pelo instável e estável, pelo novo e dado, pelo geral e particular/singular, em um estudo na perspectiva dialógica de linguagem, há ainda que se levar em conta a complexa relação (dialógica e constitutiva) entre o pesquisador e o objeto de pesquisa (os dados, que são discursos proferidos por sujeitos). Tal relação não é neutra e nem predeterminada, já que o pesquisador, em todo o processo de pesquisa, também está permeado por seu horizonte valorativo, preponderante nas suas escolhas durante o processo de pesquisa, que vão desde a delimitação do objeto até o relato da análise dos dados.

O trabalho do pesquisador inscreve-se na posição de um observador atencioso; ele é um outro (não neutro) no diálogo com os dados (discursos). Concordamos com Amorim (2004) quando, ao remeter à metáfora da hospitalidade para fazer referência ao trabalho do pesquisador, propõe que, no ato-evento de se fazer pesquisa, o pesquisador pode ser comparado tanto com o hóspede quanto com o anfitrião, ao mesmo tempo. É anfitrião à medida que recebe e agrega o universo pesquisado, abre-se para tal universo; no entanto, é hóspede à medida que se lança a essa viagem, em que se propõe a um exílio deliberado para buscar o distanciamento, o estranhamento e o questionamento em relação ao objeto. Ele (o pesquisador) abandona seu território, desloca-se em direção ao país do outro, para uma determinada escuta da alteridade, para então poder transmiti-la 
e traduzi-la (AMORIM, 2004, p. 26). Esse processo de seleção/constituição de um objeto, bem como a ação de auscultá-lo e tentar interpretá-lo já são atividades acentuadas valorativamente. Segundo Amorim (2004, p. 29), "todo objeto de pesquisa é um objeto construído e não imediatamente dado", porque o pesquisador seleciona seu objeto a partir de um determinado horizonte axiológico, permeado de uma série de jáditos (BAKHTIN, 2003[1979]) sobre o tema da pesquisa.

A relação entre pesquisador e objeto remete-nos ao dizer de Bakhtin (2003[1979]), quando o autor afirma que "toda relação de princípio é de natureza produtiva e criadora. O que na vida, na cognição e no ato chamamos de objeto só adquire determinidade na nossa relação com ele: é a nossa relação que define o objeto e sua estrutura e não o contrário." (BAKHTIN, 2003[1979], p. 4). Nesse contexto epistêmico-metodológico, estabelecer o objeto, gerar os dados de pesquisa e circunscrever os espaços de pesquisas (suas delimitações) constitui um trabalho teóricometodológico do pesquisador, cuja base é de natureza dialógica e axiológica.

Ainda sobre a relação entre pesquisador e o seu objeto de pesquisa, Sobral (2007, p. 114) propõe alguns aspectos a serem observados quando se atua no âmbito de uma pesquisa cuja base teórico-metodológica é o pensamento bakhtiniano. São eles:

- a relação entre os aspectos generalizáveis e os aspectos particulares do fenômeno, que constitui o plano teórico;

- a relação entre as expectativas do pesquisador e a realidade do fenômeno, base da construção do objeto de que o pesquisador se ocupa, que constitui o plano ético;

- o caráter de construção arquitetônica de toda pesquisa, que constitui o plano estético.

Além das questões relativas ao modo de empreender uma análise dialógica do discurso e as implicações éticas envolvidas em pesquisas dessa natureza, é preponderante tomar a língua no seu aspecto histórico e concreto, uma vez que o discurso não se constrói sobre uma determinada realidade, mas sim na relação de respondibilidade a outro discurso. Nesse sentido, não há um acesso à realidade em si, mas a um universo discursivo, que é histórico, concreto e circunscrito a uma dada situação de interação discursiva. A análise de discurso é sempre mediada pela linguagem e realizada sobre a linguagem, pois o sentido se constrói nas relações dialógicas.

E isso porque, de acordo com Bakhtin [Volochínov] (2004[1929]), a comunicação verbal não poderá jamais ser compreendida e explicada fora do vínculo com a situação concreta. Então, para se conceber a linguagem sem perder de vista o caráter dinâmico de uma abordagem de cunho sócio-histórico, é necessário considerar que o ponto de partida para a análise do discurso (materializado nos enunciados) são os estratos sociais mais amplos, para então se chegar à materialidade linguística. Assim, ressaltamos que na pesquisa de cunho dialógico há análise das marcas linguísticas. Contudo, trata-se de um olhar para a língua vista na condição de discurso, quer dizer, uma análise da linguagem em uso, do funcionamento discursivo em dada situação de interação discursiva. Tal estudo caracteriza-se por uma análise semântica que leva em conta as relações extralinguísticas, históricas e concretas, que se materializam nos enunciados, 
com vistas a construir possibilidades de compreensão sobre os sentidos promovidos no bojo das relações dialógicas.

A perspectiva da Análise Dialógica do Discurso é uma proposta de análise, uma via de investigação, uma maneira de interrogar e não um método de pesquisa ou modelo rígido de escrita (AMORIM, 2004, p. 16). Assim sendo, para a análise dos enunciados dos licenciandos em Letras-Português-EaD, apoiamo-nos em alguns parâmetros apresentados nas análises empreendidas pelo Círculo de Bakhtin, a saber:

- O estudo da esfera de atividade humana, em que se dão as interações discursivas;

- A descrição dos papéis assumidos pelos participantes da interação discursiva (licenciandos, tutores e professores), analisando as relações simétricas/assimétricas entre os interlocutores na produção de discurso;

- O estudo do cronotopo (o espaço-tempo discursivo) dos enunciados;

- O estudo do horizonte temático-valorativo dos enunciados;

- A análise das relações dialógicas que apontam para a presença de assimilação de discursos já-ditos e discursos prefigurados, discursos bivocais, apagamentos de sentidos, contraposições, enquadramentos, reenunciação de discursos e reacentuações de discursos.

O foco da análise recaiu sobre os elementos constitutivos dos enunciados dos licenciandos que apontam para os modos de discursivização sobre a atuação do professor de LP, perscrutando as regularidades materializadas nos enunciados. No entanto, ressaltamos que os aspectos acima mencionados são parâmetros norteadores para nossa investigação e busca da compreensão dos enunciados, não categorias analíticas estanques e engessadas.

Com relação aos objetos de discurso a partir dos quais os licenciandos se posicionam, partimos inicialmente da acepção de que as situações de interação se dão em um espaço de ensino formal/oficial, portanto institucionalizado e constituído por determinadas regras/regularidades. Isso significa dizer que os licenciandos são chamados a se posicionar sobre assuntos referentes às disciplinas cursadas, sempre com vistas à construção de conhecimento em um processo de ensino e aprendizagem. Nas situações de ensino e aprendizagem em espaços formalizados, insere-se uma série de expedientes de produção dos discursos, tais como: conteúdos de ensino e aprendizagem; atividades a serem desenvolvidas e postadas no Ambiente de Ensino e Aprendizagem (AVEA); questões relativas à avaliação e ao desempenho dos licenciandos; e avaliação da disciplina e do curso como um todo. Nesse conjunto de objetos discursivos, em contexto de uma graduação em licenciatura, estão em pauta saberes que permeiam a formação inicial de professores.

O horizonte epistêmico-metodológico aqui apresentado mostrou-se produtivo para o estudo dos enunciados dos licenciandos produzidos na $\mathrm{EaD}$, uma vez que não houve categorias prévias, imutáveis, engessadas, e sim alguns parâmetros mais amplos que nos possibilitaram observar as regularidades e irregularidades, as estabilidades e instabilidades desse discurso.

A seguir, apresentamos as regularidades observadas nos dados da pesquisa no tocante às concepções de conteúdos de ensino e aprendizagem na disciplina de LP. 


\section{QUE DIZEM OS LICENCIANDOS SOBRE OS CONTEÚDOS DE ENSINO E APRENDIZAGEM NA DISCIPLINA DE LÍNGUA PORTUGUESA?}

A atuação do professor de LP está intimamente ligada aos conteúdos de ensino e aprendizagem dessa disciplina, que foram historicamente constituídos na esfera escolar. No que se refere aos discursos dos sujeitos da pesquisa (licenciandos em Letras) sobre os conteúdos de ensino e aprendizagem, vemos um embate entre o discurso da tradição do ensino de LP e o discurso teórico, oriundo das interações nas disciplinas que tematizam as questões inerentes ao ensino de língua materna.

Os licenciandos renunciam, em seus enunciados, o discurso da tradição do ensino de LP sobre os conteúdos de ensino e aprendizagem por meio da referência ao ensino da gramática tradicional. Ao discursivizarem a gramática como conteúdo de ensino e aprendizagem da disciplina, os licenciandos assumem posicionamentos distintos. Em alguns enunciados vemos um movimento dialógico de assimilação (RODRIGUES, 2001) do discurso da gramática como conteúdo de ensino e aprendizagem; já, em outros enunciados, há um movimento dialógico de distanciamento (RODRIGUES, 2001) face a esse discurso.

Nos enunciados a seguir, identificamos o discurso da tradição do ensino de LP no tocante aos conteúdos de ensino e aprendizagem nessa disciplina:

\footnotetext{
Até esse estágio do curso, o que você considera prioridade em termos de conteúdo de ensino-aprendizagem na disciplina de Língua Portuguesa? O curso de graduação em Letras está atendendo a essas prioridades de formação?

Q1 ${ }^{1}$ : $O$ curso é muito bom, porém sinto falta de disciplinas que trabalhem gramática. (Sou insegura p/trabalhar em sala de aula).

Q2: E bom, mas deixa a desejar no sentido do estudo da gramática, acho que vai fazer falta quando estivermos em sala.

Q3: Gramática. Acredito que precisaria trabalhar mais essa área.

Q4: A prioridade acho que seria a gramática.

Q5: A gramática, a literatura e a linguística. Em literatura e linguística sim.
}

Como você avalia o curso de Letras-Português-EaD até as disciplinas que você cursou no que se refere à formação/preparação para ser professor de Língua Portuguesa?

Q6: Eu achei as disciplinas ótimas, mas to sentindo falta de gramática.

Os licenciandos apontam a gramática como principal conteúdo de ensino e aprendizagem e também manifestam a ausência da gramática no curso de Letras. Tais enunciados evidenciam um movimento dialógico de assimilação (RODRIGUES, 2001)

\footnotetext{
${ }^{1}$ Os dados inseridos no corpo da análise correspondem exatamente ao que foi textualizado pelos sujeitos da pesquisa, ou seja, não houve nenhuma espécie de revisão de texto. Com o objetivo de retratar os dados dos fóruns tais quais inseridos no AVEA, nós apresentamos também as características do suporte (os quadros, as informações sobre dia e data de postagem). Porém, os fóruns apresentam originalmente a fotografia dos interlocutores, que foi excluída para apresentação neste artigo. Já o destaque em negrito, inserido em partes dos enunciados pela pesquisadora, ressalta o tópico em análise. Para indicar a natureza do dado inserido na análise, utilizamos as seguintes siglas: AA-Atividades Avaliativas; F-Fórum; e QQuestionário. Cabe destacar que os nomes mencionados na transcrição dos dados são fíctícios.
} 
do discurso da tradição do ensino de LP no que se refere aos conteúdos de ensino e aprendizagem, uma vez que considera a gramática como conteúdo privilegiado (para trabalhar em sala de aula) na disciplina. Por isso, enunciam a ausência de gramática no curso como um problema/uma lacuna para a sua atuação docente. De forma explícita, os licenciandos relacionam, a gramática ao conteúdo de ensino e aprendizagem na disciplina, quando dizem: [...] deixa a desejar no sentido do estudo da gramática, acho que vai fazer falta quando estivermos em sala; sinto falta de disciplinas que trabalhem gramática. (Sou insegura p/trabalhar em sala de aula).

A orientação avaliativa em relação à gramática como conteúdo de ensino e aprendizagem apresenta uma certa regularidade, tendo em vista que primeiramente enunciam uma valoração positiva em relação ao curso, como em: as disciplinas são ótimas; o curso é muito bom; é bom. Em seguida, inserem um operador argumentativo que indica contrariedade - mas/porém - e só então apresentam sua posição valorativa sobre a gramática com conteúdo de ensino e aprendizagem, mais especificamente, $o$ sentimento de ausência de gramática nas disciplinas do curso, que os prepararia para ensinar português (gramática) na escola básica.

Os dados coletados mostram reenunciações discursivas que não são novas, mas estão dialogicamente ligadas aos já-ditos. Por exemplo, o sentimento de falta de gramática foi também identificado por Barbosa (2004), quando pesquisava o discurso do graduando em Letras na fase final sobre o ensino de língua materna, na modalidade presencial no sudeste e norte do Brasil. Assim, no discurso sobre a ausência de gramática, emerge o peso do discurso da tradição do ensino de língua no Brasil, que se faz ouvir nos enunciados dos licenciandos, pois, na sua concepção, a gramática é o conteúdo por excelência na disciplina de LP. A força do discurso da tradição do ensino de LP se ancora na primazia dos estudos gramaticais (de cunho prescritivo e conceitual) no ensino de língua em todo o século XIX e grande parte do século XX. Nesse período, o ensino pautou-se em uma perspectiva de ensino de gramática, baseada em uma única modalidade da língua portuguesa, conforme historia Soares (2002). Segundo Faraco (2008, p. 185), "tradicionalmente, sempre se identificou, no Brasil, o ensino de português com o ensino da gramática". Por muito tempo a concepção de conteúdo de ensino e aprendizagem na disciplina escolar de LP ancorou-se em uma perspectiva gramatical, sobretudo, em uma gramática prescritiva e conceitual centrada fortemente em uma abordagem metalinguística, como problematizado no âmbito das pesquisas na área do ensino e aprendizagem de língua materna (BRITTO, 1997; GERALDI, 1991; SOARES, 2002).

Em outra situação de interação, mais precisamente em uma das atividades avaliativas, a gramática também foi apontada como conteúdo de ensino e aprendizagem:

O que é ensinar Lingua Portuguesa e Literatura?

AA1-Rute: O professor deve ensinar tanto a gramática quanto a literatura.

Afinal, qual é a função do professor de Lingua Portuguesa e Literatura?

AA2-Rosana: Mostrar as regras da gramática, dando uma base para quando precisarem se expressar formalmente [...].

AA3-Camila: [...] o enfoque dado à gramática tem o compromisso de levar o aluno a se expressar melhor e a construir textos mais coerentes. 
Nesses enunciados, os licenciandos reenunciam a gramática como conteúdo de ensino e aprendizagem, como nos excertos anteriores, porém, agregam outros conteúdos, com, por exemplo, o ensino de Literatura ([...] ensinar tanto a gramática quanto a literatura.). Essa perspectiva aponta para uma divisão clássica da disciplina de LP, ainda não superada: conteúdos de língua e conteúdos de literatura.

Já quando dizem que é preciso mostrar as regras da gramática, dando uma base para quando precisarem se expressar formalmente, ou ainda que o enfoque dado à gramática tem o compromisso de levar o aluno a se expressar melhor e a construir textos mais coerentes, os licenciandos enunciam um discurso amplamente difundido de que o conhecimento das regras normativas garante um uso efetivo da linguagem em diversos contextos comunicativos. Segundo Britto (1997, p. 169), existe uma "ilusão de que o estudo da gramática tradicional permite que se expanda a capacidade comunicativa e, por extensão o domínio de outros saberes". Quando a licencianda Camila (AA3) afirma que a gramática oportuniza a construção de textos mais coerentes, ela relaciona norma-padrão ao processo de produção de textos. De acordo com Britto (1997, p. 176), “[...] o ensino da escrita não se confunde com o mero ensino de regras de uso [...] e, muito menos, com o ensino de norma culta. $\mathrm{O}$ acesso à escrita implica $\mathrm{o}$ reconhecimento de forma de discurso e o domínio de sistemas de referência específicos". Mais que ilusões ou equívocos, essas concepções são também discursos que representam as forças centrípetas (BAKHTIN, 1998[1975]) da língua, cujos discursos objetivam a perpetuação da concepção de língua única.

Observamos também enunciados em que os licenciandos tematizam o ensino de gramática. No entanto, esses enunciados evidenciam um movimento dialógico de distanciamento (RODRIGUES, 2001) da concepção de gramática como conteúdo central na disciplina de LP, como vemos a seguir:

\title{
O que é ensinar Lingua Portuguesa e Literatura?
}

AA4-Pedro: [...] precisamos focar o ensino de língua, de maneira abrangente e na sua totalidade, dando espaço que a literatura merece, e não ensinando só a gramática, que é de difícil assimilação pelos alunos, levando os alunos a considerar essas aulas chatas $e$ modorrentas, levando-os a ter sempre um pé atrás com as aulas de português.

AA5-João: É colocar o aluno no processo de aprendizagem visando não ensinar-lhes somente as práticas normativas de ensino, a "gramática", como se dizia no tempo do vovô, mas também sua inclusão na sociedade, como parte dela, ensinar na vida pessoal e profissional. Fazer com que o aluno dê conta do uso da linguagem oral e escrita de forma crítica, criativa e construtiva.

F1

\author{
Re: Fórum 1 \\ por Julia - segunda, 20 setembro 2010, 12:04
}

Penso que cursos de formação continuada ou capacitação que envolvem o tema leitura e/ou literatura também deveriam ser feitos por professores de outras áreas. Por experiência própria, já presenciei professores que não possuem uma visão positiva sobre leitura ou literatura nas escolas. Pensam que o professor de língua portuguesa deve ficar preso ao ensino de gramática, sintaxe e de dissertação e "vencer" o livro ou a apostila. Isto é um absurdo. (Isto não vem ao caso, é apenas um desabafo). A leitura é apaixonante. E com a pouca experiência que possuo, penso que se deveria ter uma disciplina apenas para leitura/literatura nas escolas, $[\ldots]$ 
De modo geral, esses enunciados refutam o ensino de gramática tradicional, trazendo alguns já-ditos sobre o tema: o estudo gramatical é difícil (não ensinando só a gramática que é de difícil assimilação pelos alunos [...]); o ensino gramatical torna a aula maçante para os alunos ([...] levando os alunos a considerar essas aulas chatas e modorrentas). Ainda para manifestar o distanciamento do discurso da tradição do ensino de LP, que concebe a gramática como único conteúdo de ensino e aprendizagem, há o uso de expressões avaliativas e ironia (do tempo do vovô), qualificando a gramática como um conteúdo ultrapassado/antiquado.

Mas, embora desqualifiquem o conteúdo gramatical, os licenciandos (AA4; AA5) não se posicionam a favor do abandono total do ensino gramatical, e sim a favor de uma mistura do ensino de gramática com outros conteúdos, como vemos em: [...] dando espaço que a literatura merece, e não ensinando só a gramática; [...] não ensinar-lhes somente as práticas normativas de ensino, [...] mas também sua inclusão na sociedade, como parte dela, ensinar na vida pessoal e profissional. Fazer com que o aluno dê conta do uso da linguagem oral e escrita de forma crítica, criativa e construtiva. Ao dizer que é preciso focar o ensino de língua, de maneira abrangente e na sua totalidade, parecenos que Pedro (AA5) encaminha seu enunciado no sentido de apontar novos conteúdos de ensino e aprendizagem de LP, mas logo essa expectativa é frustrada, tendo em vista que novamente enuncia a clássica organização da disciplina - gramática e literatura. $O$ licenciando reenuncia um discurso sobre a perda de espaço dos estudos literários na disciplina, quando diz que é preciso dar o espaço que a literatura merece, e não ensinar só a gramática. Vê-se que, embora defenda um maior espaço para o ensino da literatura, o licenciando não se posiciona pela exclusão/diminuição do ensino de conteúdos gramaticais.

De modo similar, João (AA5) manifesta-se pela manutenção do ensino do conteúdo gramatical (não ensinar-lhes somente as práticas normativas de ensino, a "gramática"), com adição de novos conteúdos, que se referem ao uso da linguagem oral e escrita.

Julia, por sua vez, além de manifestar um movimento dialógico de distanciamento, ao refutar o ensino de conteúdos gramaticais, desqualifica também os conteúdos ligados à redação escolarizada (ao ensino de gramática, sintaxe e de dissertação). A licencianda constrói seu enunciado a partir do enunciado do outro (professores que não possuem uma visão positiva sobre leitura ou literatura nas escolas). Melhor dizendo, o discurso do outro é usado como argumento para afirmar o seu posicionamento contrário aos conteúdos concebidos como tradicionais. Ela acentua sua posição valorativa sobre os conteúdos de ensino e aprendizagem na disciplina de LP, quando diz: Isto é um absurdo. E, ainda, sobre o enunciado da licencianda (F1), vale destacar que ela também dicotomiza leitura e literatura (não possuem uma visão positiva sobre leitura ou literatura nas escolas). A licencianda não compreende a leitura (o que inclui a leitura de textos literários) como conteúdo intrínseco à disciplina, já que, na sua visão, seria necessário criar uma disciplina que trabalhasse especificamente com a leitura (penso que se deveria ter uma disciplina apenas para leitura/literatura nas escolas). 
Percebemos que, embora refutem os conteúdos de ensino aprendizagem considerados tradicionais, sobretudo, o conteúdo gramatical, os licenciandos trazem os já-ditos que os constituem, ou seja, os novos conteúdos se ajustam/se acomodam aos já estabelecidos na cultura escolar. Os enunciados dos licenciandos sobre os conteúdos de ensino e aprendizagem, assentado no discurso da tradição do ensino de LP, choca-se contra o discurso teórico do curso, advindo das interações em que foram tematizados conteúdos de ensino e aprendizagem na disciplina.

A perspectiva teórica das disciplinas do curso que mais especificamente discutem os conteúdos de LP orienta-se por pesquisas no campo da Linguística Aplicada. Nesse contexto epistemológico, ocorreu nas últimas três décadas um debate intenso sobre a necessidade de mudança no ensino de LP no que se refere às finalidades dessa disciplina e, em decorrência, aos conteúdos de ensino e aprendizagem. Já na década de 1990, Rodrigues (1999) ponderava que o fracasso escolar no ensino de língua tem girado em torno, principalmente, de um ensino-aprendizagem voltado para a questão da metalinguagem, ou para aspectos formais de leitura e da escrita, o que se convencionou chamar de ensino tradicional na disciplina de LP.

De acordo com Britto (1997), pesquisadores como Geraldi (1984) e Franchi (1987) propuseram, na década de 1980, que o trabalho na escola se orientasse por uma concepção operacional e reflexiva da linguagem, que toma o texto como ponto de partida para o trabalho de leitura e produção de texto (orais e escritos), mediado pela prática de análise linguística. Essa proposta foi assimilada pelos documentos oficiais de ensino como Parâmetros Curriculares Nacionais (PCNs) e Propostas Curriculares de secretarias municipais e estaduais de ensino.

Esse percurso histórico da disciplina de LP, bem como as reflexões sobre as mudanças necessárias no ensino de língua materna, foi apresentado aos licenciandos nas disciplinas de Linguística Textual, Linguística Aplicada: Ensino de Língua Materna e Metodologia do Ensino de Língua Portuguesa e Literatura e também nos minicursos Gêneros discursivos e Formação do leitor. Além disso, várias discussões propostas em atividades e em fóruns encaminharam o diálogo no sentido de problematizar as mudanças no ensino de LP no que se refere à concepção de linguagem, às finalidades da disciplina e a conteúdos de ensino e aprendizagem.

Por meio das interações na formação inicial, os licenciandos entraram em contato com essa perspectiva epistemológica (discurso da mudança/do novo) sobre os objetivos e os conteúdos de ensino e aprendizagem. Por isso, observamos um processo de assimilação dos discursos oriundos das interações no curso, mais precisamente das disciplinas e minicursos mencionados anteriormente, como podemos observar a seguir:

A partir das disciplinas cursadas durante o curso, como você pensa o ensino de Língua Portuguesa? Dito de outro modo, quais são as finalidades/objetivos da disciplina? Quais os seus conteúdos?

Q7: Vejo que o curso segue para o caminho da mudança na formação do professor de LP, a exemplo é que não trabalhamos diretamente com a gramática, algo que nas salas de aulas hoje, ainda alguns professores incluem em seu conteúdo didático.

Q8: $O$ ensino deve ser tido como um processo de troca e dinâmico, tendo como finalidade maior a compreensão da língua como falantes e escritores. Desta forma, nós como professores devemos auxiliar no processo de construção de conhecimento, passando por conteúdos como: gêneros de discurso, análises lingüísticas e também gramática. 
Os enunciados dos licenciandos apontam para um processo de assimilação do discurso teórico apresentado a eles sobre novos conteúdos de ensino na disciplina de LP. Contudo, eles ainda não conseguem apresentar uma definição mais acurada/refinada sobre esse outro olhar para o conteúdo de ensino e aprendizagem dessa disciplina (Vejo que o curso segue para o caminho da mudança na formação do professor de LP, a exemplo é que não trabalhamos diretamente com a gramática [...]). Na visão do licenciando (Q7), há uma mudança em processo, mas ele não sabe bem qual é; ele afirma também que o curso aponta para esse novo, ao contrário da escola, que ainda não assimilou essa mudança (algo que nas salas de aulas hoje, ainda alguns professores incluem em seu conteúdo didático). O caminho da mudança na formação do professor, na visão do licenciando, tem relação com a discussão emblemática sobre ensinar ou não gramática, e, quando diz que não trabalhamos diretamente com gramática, parece haver uma referência à noção de análise linguística ${ }^{2}$, que se articula às práticas de leitura e de escrita em uma perspectiva operacional e reflexiva de linguagem. O licenciando ainda não consegue articular/textualizar com muita propriedade esse conceito porque está ainda em processo de assimilação do discurso sobre os novos conteúdos de ensino e aprendizagem.

Já em Q8, a expressão análise linguística é usada de forma explícita e separadamente da menção à gramática, como se observa em: [...] passando por conteúdos como: gêneros de discurso, análises lingüísticas e também gramática. Nesse enunciado, podemos perceber que a noção de trabalho operacional e reflexivo da linguagem permeia o discurso-resposta do licenciando. Isso, porém, não é de todo um discurso dele, tendo em vista que o agrupamento apresentado mostra-se pouco explicativo, se pensarmos que os gêneros do discurso podem ser vistos como o meio para se chegar às práticas de linguagem (leitura, escrita, análise linguística) e que o trabalho com análise linguística implica também trabalhar com uma noção de gramática.

Destacam-se também como regularidade os enunciados que valoram, de forma mais esparsa, o trabalho com gêneros do discurso, escrita, leitura e oralidade, considerando-os como conteúdos de ensino e aprendizagem na disciplina de LP, como podemos observar a seguir:

Até esse estágio do curso, o que você considera prioridade em termos de conteúdo de ensino-aprendizagem na disciplina de Língua Portuguesa? O curso de graduação em Letras está atendendo a essas prioridades de formação?

Q9: Ampliar a competência linguística e discursiva dos alunos, tornando-os bons leitores e produtores de todos os tipos de textos - (gêneros, leitura, produção textual).

Q10: Leitura, escrita e oralidade. Acredito que sim.

Q11: As prioridades são proficiência em leitura e escrita e novos conhecimentos literários.

Q12: Produção textual. Está.

Q13: É muito importante a Produção Textual.

Q14: A leitura é muito importante, sim o curso está atendendo as prioridades.

Q15: A formação crítica do leitor. Acredito que sim.

\footnotetext{
${ }^{2}$ Conforme propõe Geraldi (2002[1991], p. 189), a análise linguística é concebida como um conjunto de atividades que tomam a linguagem como seu objeto de reflexão.
}

ROHLING, Nívea. Conteúdos de ensino na disciplina de Língua Portuguesa: o embate entre o discurso da tradição e o discurso da mudança. Linguagem em (Dis)curso - LemD, Tubarão, SC, v. 14, n. 1, p. 123-137, jan./abr. 2014. 
Q16: Trabalhar com os gêneros do discurso que irão contribuir com as práticas sociais dos alunos. Acredito que o curso está sim atendendo a essas prioridades de formação. Q17: Acredito que seja levar os alunos a entender e usar a função social da fala e escrita.

AA6-Rose: [...] O professor de Língua Portuguesa tem, necessariamente, o texto como objeto do ensino da sua disciplina e deve ter o livro didático apenas como material de apoio para suas aulas [...].

Podemos dizer que esses enunciados mostraram-se mais explícitos no sentido de reenunciar o discurso teórico das disciplinas, orientadas pela perspectiva operacional e reflexiva do ensino e aprendizagem da linguagem, ao mencionarem o trabalho com os gêneros, a leitura e escrita, a função social da escrita e do texto. No entanto, dos exemplos apresentados, somente Q9 e Q10 apresentam uma sequência (um conjunto) de conteúdos que remetem à concepção de ensino operacional e reflexivo da linguagem (gêneros, leitura, produção textual; Leitura, escrita e oralidade). Os demais apontam conteúdos isolados/esparsos e desarticulados (leitura e escrita e novos conhecimentos literários; Produção textual; leitura; formação crítica do leitor; gêneros do discurso; função social da fala e escrita).

Em alguns enunciados, o discurso teórico, oriundo das interações no curso, é invocado pelos licenciandos. Em outros termos, os sujeitos acentuam os conteúdos que estavam na emergência do acontecimento da aula virtual nas disciplinas em questão. Contudo, é preciso destacar que pouco discursivizam a concepção de linguagem como interação. Já os conteúdos de ensino e aprendizagem que remetem a essa perspectiva teórica (leitura, escrita, gêneros do discurso, por exemplo) são mencionados com mais frequência por eles. Podemos aventar que os licenciandos tematizam mais explicitamente os conteúdo de ensino, porque, na perspectiva deles, parecem ser um objeto mais concreto. A assimilação de uma concepção de linguagem, por seu turno, parece remeter a uma natureza estritamente conceitual. Porém, sabemos que ambos (concepção de conteúdos de ensino e aprendizagem e concepção de linguagem) são produtos da pesquisa, do exercício teórico, ou seja, uma prática teórica (FURLANETTO, 2010).

$O$ fato é que os licenciandos discursivizaram os conteúdos de ensino e aprendizagem da disciplina de LP sob a perspectiva operacional e reflexiva da linguagem de forma mais recorrente, mesmo sem estabelecer relação com a concepção de linguagem que sustenta tais conteúdos. Isso nos faz refletir que os licenciandos veem os novos conteúdos de ensino e aprendizagem na disciplina à luz de uma concepção antiga/anterior de linguagem, que já estava constituindo esses sujeitos antes de seu ingresso no curso, remetendo-nos à afirmação de Rojo (2001, p. 332): “as práticas cristalizadas na tradição de sala de aula acabam se sobrepondo a toda formação recente que se possa ministrar e 'parasitam' novas práticas". E, ainda, há uma "bricolagem entre objetos de ensino fixos - típicos da escola e cristalizados por uma tradição escolar do ensino [...] - e objetos de ensino fluídos - legitimados pelos usos acadêmicos e documentos oficiais e vistos como 'inovadores' (o ensino dos gêneros textuais, por exemplo).” (BUNZEN, 2006, p. 82, grifos do autor). Nesse sentido, corre-se o risco de que os novos conteúdos de ensino e aprendizagem sejam tomados tão somente na perspectiva instrumental, destituindo, assim, o caráter ideológico e crítico que implica um trabalho a partir da concepção de língua como interação sociodicursiva. 
A análise mostrou que os enunciados advindos da experiência pregressa de escolarização dos licenciandos, ancorados na tradição do ensino de LP, correspondem a discursos internamente persuasivos (BAKHTIN, 1998[1975]) e se mostram, como nos casos aqui exemplificados, mais fortes/arregimentados/sedimentados que o discurso teórico advindo do curso no que se refere aos novos conteúdos de ensino e aprendizagem.

No que se refere aos conteúdos de ensino e aprendizagem, o discurso da tradição do ensino de LP se fez ouvir pelos dizeres sobre a ausência de gramática no curso, o que, no olhar de alguns licenciandos, deixa-os inseguros para atuar como professores, porque consideram a gramática como o principal conteúdo de ensino e aprendizagem na disciplina.

Porém, algumas vozes mostraram que se está operando uma ressignificação/uma assimilação da noção de análise linguística como uma das práticas que fazem parte dos objetos de ensino de LP hoje. Mas, como mostramos nesta análise, essa perspectiva ainda se revela muito misturado/imbricado entre o discurso já significado pelos licenciandos (discurso da tradição) e o discurso oriundo das interações do curso, que é para os licenciandos um discurso em processo de assimilação; são "vozes ainda fracas, idéias ainda não inteiramente manifestadas [...] uma palavra futura ainda latente" (BAKHTIN, 2008 [1963], p. 101, grifo de autor).

Em síntese, apesar de os licenciandos tematizarem os novos objetos de ensino e aprendizagem (leitura, produção de textos e gêneros discursivos), que representam o discurso do novo/da mudança, o discurso mais arregimentado em seus enunciados é o discurso da tradição do ensino de língua materna.

\section{REFERÊNCIAS}

AMORIM, M. O pesquisador e seu outro: Bakhtin nas ciências humanas. São Paulo: Musa Editora, 2004. BAKHTIN, M. M.; [VOLOCHÍNOV, V. N.]. Marxismo e filosofia da linguagem: problemas fundamentais do método sociológico na ciência da linguagem. 11. ed. Tradução do francês por Michel Lahud e Yara F.Vieira. São Paulo: Hucitec, 2004[1929].

BAKHTIN, M. M. Problemas da poética de Dostoiévski. Tradução do russo, notas e prefácio de Paulo Bezerra. 4. ed. Revista e ampliada. Rio de Janeiro: Forense Universitária, 2008[1963].

Questões de literatura e de estética - a teoria do romance. Tradução do russo por Aurora Fornoni $\overline{B e r n a r d i n i ~ e t ~ a l . ~ S a ̃ o ~ P a u l o: ~ U N E S P ; ~ H u c i t e c, ~ 1998[1975] . ~}$

Estética da criação verbal. Tradução do russo por Paulo Bezerra. 4. ed. São Paulo: Martins Fontes, 2003[1979].

BARBOSA, M. V. Entre o sim e o não, a permanência: o discurso do graduando em Letras sobre o ensino da língua materna. 2004. 191f. Dissertação (Mestrado em Linguística). Instituto de Estudos da Linguagem da Universidade Estadual de Campinas (UNICAMP), Campinas, 2004.

BRAIT, B. Análise e Teoria do Discurso. In: BRAIT, B. (Org.). Bakhtin: Outros conceitos-chave. São Paulo: Contexto, 2006. p. 9-31.

A natureza dialógica da linguagem: formas e graus de representação dessa dimensão constitutiva. In: FARACO, C. A.; TEZZA, C.; CASTRO, G. Diálogos com Bakhtin 4. ed. Curitiba: Editora da UFPR, 2007. p. 61-80. . Bakhtin: dialogismo e polifonia. São Paulo: Contexto, 2009. 
BRITTO, L. P. L. A sombra do caos: ensino de língua x tradição gramatical. Campinas (SP): Mercado de Letras, 1997.

BUNZEN, C. Da era da composição à era dos gêneros: o ensino de produção de texto no ensino médio. In: BUNZEN, Clécio; MENDONÇA, Marcia. (Orgs.). Português no ensino médio e formação do professor. São Paulo: Parábola, 2006. p. 139-161.

FARACO, C. A. Linguagem \& diálogo: as idéias lingüísticas do Círculo de Bakhtin. São Paulo: Parábola, 2009[2003].

. Norma Culta Brasileira: desatando alguns nós. São Paulo: Parábola Editoria, 2008.

FRANCHI, C. Criatividade e gramática. Trabalhos em Linguística Aplicada, 9, p. 5-45, 1987.

FURLANETTO, M. M. Do discurso monológico da consciência aos gêneros do discurso. Revista Brasileira de Linguística Aplicada, v. 10, n. 2, p. 301-324, 2010. Disponível em:

$<$ http://www.periodicos.letras.ufmg.br/rbla/arquivos/80.pdf>. Acesso em: 20/08/2011.

GERALDI, J. W. (Org.). O texto na sala de aula. 2. ed. São Paulo: Ática, 1984.

GERALDI, J. W. Portos de passagem. 4. ed. São Paulo: Martins Fontes, 2002[1991].

MIOTELLO, V. A construção turbulenta das hegemonias discursivas: o discurso neoliberal e seus confrontos. 2001. 339f. Tese (Doutorado) - Programa de Pós-Graduação em Lingüística Aplicada, Instituto de Estudos da Linguagem, Universidade Estadual de Campinas. Campinas, SP, 2001.

PONZIO, A. A revolução bakhtiniana: o pensamento de Bakhtin e a ideologia contemporânea. Coordenação de tradução Valdemir Miotello. São Paulo: Contexto, 2008[1998].

Prefácio de Para uma filosofia do ato responsável. Tradução de Carlos Alberto Faraco e Valdemir Miotello. São Carlos: Pedro \& João Editores, 2010. p. 9-38.

RODRIGUES, R. H. As diferentes esferas sócio-discursivas como critério para a elaboração de currículos. Intercâmbio - Uma Publicação de Pesquisas em Lingüística Aplicada, São Paulo, vol. VIII, p. 93-100, 1999.

A constituição e o funcionamento do gênero jornalístico artigo: cronotopo e dialogismo. 2001. 356f. Tese (Doutorado) - Programa de Estudos Pós-Graduados em Linguística Aplicada e Estudos da Linguagem. Pontifícia Universidade Católica de São Paulo, São Paulo, 2001.

. Os gêneros do discurso na perspectiva dialógica da linguagem: a abordagem de Bakhtin. In: MEURER, J. L.; BONINI, A.; MOTA-ROTH, D. (Orgs.). Gêneros: teorias, métodos e debates. São Paulo: Parábola Editorial, 2005. p. 152-183.

ROJO, R. H. R.. Modelização Diadática e planejamento: duas práticas esquecidas do professor? In: KLEIMAN, Â. B. (Org.). A formação do professor: perspectivas da lingüística aplicada. Campinas, SP: Mercado de Letras, 2001. p. 313-335.

SOBRAL, A. Ético e estético: na vida, na arte e na pesquisa em Ciências Humanas. In: BRAIT, B. Bakhtin: conceitos-chave. 4. ed. São Paulo: Contexto, 2007. p. 11-36.

SOARES, M. Português na escola - História de uma disciplina curricular. In: BAGNO, M. (Org.). Lingüística da norma. São Paulo: Edições Loyola, 2002. p. 155-177.

\title{
Recebido em: 27/06/13. Aprovado em:18/02/14.
}

Title: Contents and learning in the discipline of Portuguese language: the clash between the discourse of tradition and the discourse of change

\begin{abstract}
Author: Nivea Rohling
Abstract: This article presents an analysis of the enunciations of the students, in a distance education Language and Literature Teaching Degree course at a Public University in southern Brazil, concerning the students' conceptions on teaching contents and learning in the discipline of Portuguese Language. The theoretical and methodological basis is the Dialogic Discourse Analysis of the Bakhtin Circle. The survey data consist of 106 discussion forums, 59 enunciations in evaluation activities, posted in the virtual environment for teaching and learning in the period from 2007 to 2011, and data generated by means of a questionnaire, answered by 61 undergraduates in their respective local teaching facilities. The analysis points to a clash between the discourse of tradition in the teaching of Portuguese language and the discourse of change.
\end{abstract}

Keywords: Teacher training. Teaching contents. Discourse of tradition.

ROHLING, Nívea. Conteúdos de ensino na disciplina de Língua Portuguesa: o embate entre o discurso da tradição e o discurso da mudança. Linguagem em (Dis)curso - LemD, Tubarão, SC, v. 14, n. 1, p. 123-137, jan./abr. 2014. 
Título: Contenidos de la enseñanza en la disciplina de lengua portuguesa: el choque entre discurso de tradición y cambio de dirección

Autor: Nivea Rohling

Resumen: En este artículo se presenta un análisis de las enunciaciones de los estudiantes de un curso de Licenciatura en Letras-Portugués-ED de una Universidad Pública en el sur de Brasil en relación con las concepciones de contenidos de enseñanza y aprendizaje en la signatura de Lengua Portuguesa. La base teórica y metodológica es parte del Análisis Dialógico del Discurso del Círculo Bajtín. Los datos del estudio consisten en: 106 foros de discusión, 59 declaraciones de actividades de evaluación, publicado en el entorno virtual de enseñanza y aprendizaje en el período 2007-2011, y los datos generados a través de un cuestionario respondido por 61 estudiantes en sus respectivos polos de apoyo para enseñanza en clase. El análisis apunta para un enfrentamiento entre el discurso de la tradición en la enseñanza de la lengua portuguesa y el discurso del cambio.

Palabras-clave: La formación inicial del profesorado. Contenido de enseñanza y el aprendizaje. Discurso de tradición. 